\title{
Establishment of Functional and Molecular Ultrasound for Breast Cancer Xenograft Imaging
}

\section{Etablierung von funktionellem und molekularem Ultraschall für die Bildgebung von Brustkrebsmodellen}

\author{
Author \\ J. Bzyl \\ Affiliation \\ Institute for Experimental Molecular Imaging, RWTH Aachen University, Aachen
}

\author{
Key words \\ - breast \\ - ultrasound \\ - angiogenesis \\ $\checkmark$ animal investigations
}

This article was awarded with the Promotionspreis 2013

received $\quad 16.12 .2013$ accepted 10.2.2014

Bibliography

Dol http://dx.doi.org/ 10.1055/s-0034-1366187

Published online: 2014

Fortschr Röntgenstr 2014; 186:

377-379 @ Georg Thieme

Verlag KG Stuttgart · New York . ISSN 1438-9029

\section{Correspondence}

Frau Dr. Jessica Bzyl

Institute for Experimental

Molecular Imaging, RWTH

Aachen University

Pauwelsstraße 20

52074 Aachen

Germany

Tel.: ++49/2 41/8080116

Fax: ++ 49/2 41/803382006

jessica.bzyl@gmx.de

\section{Zusammenfassung \\ $\nabla$}

Die vorliegende Arbeit wurde in European Radiology und als Dissertation an der RWTH Aachen veröffentlicht und wurde am Institut für Experimentelle Molekulare Bildgebung der RWTH Aachen durchgeführt.

\section{Abstract \\ $\nabla$}

The present work was originally published in European Radiology and as a PhD thesis at the RWTH Aachen University and was conducted at the Institute for Experimental Molecular Imaging at the RWTH Aachen University.

Citation Format:

- Bzyl J. Establishment of Functional and Molecular Ultrasound for Breast Cancer Xenograft Imaging. Fortschr Röntgenstr 2014; 186: 377379

trasound this was BR55. A heterodimer selectively binding to human and murine vascular endothelial growth factor receptor type 2 (VEGFR-2) was conjugated to DSPE-PEG-2000-NH2 which was then incorporated into the microbubbles' lipid shell. A detailed description can be found in [5]. VEGFR-2 is one of the most characterized tumor-angiogenic markers. For functional ultrasound BR38 was applied, consisting of non-targeted, PEGylated microbubbles, i.e. microbubbles with a Polyethylenglycol (PEG) brush. Their lipid shell contains DPPE-MPEG 5000 that contributes to a long persistence of the microbubbles in the blood system [6]. Both, BR38 and BR55 were designed for clinical application.

In the first study the circulating characteristics of BR55 and BR38 microbubbles in healthy mice and their ability to characterize the angiogenic activity of differently aggressive human breast adenocarcinomas were evaluated [1]. BR38 showed a long blood half-life of more than ten minutes and a relatively slow uptake by the liver. For clinical use the long circulation time of BR38 might be beneficial because it allows an intensive examination of one or even several different organs. The VEGFR-2 targeted BR55 microbubbles had a relatively short blood half-life of about $4 \mathrm{~min}$. An early accumulation of these microbubbles was ob- 


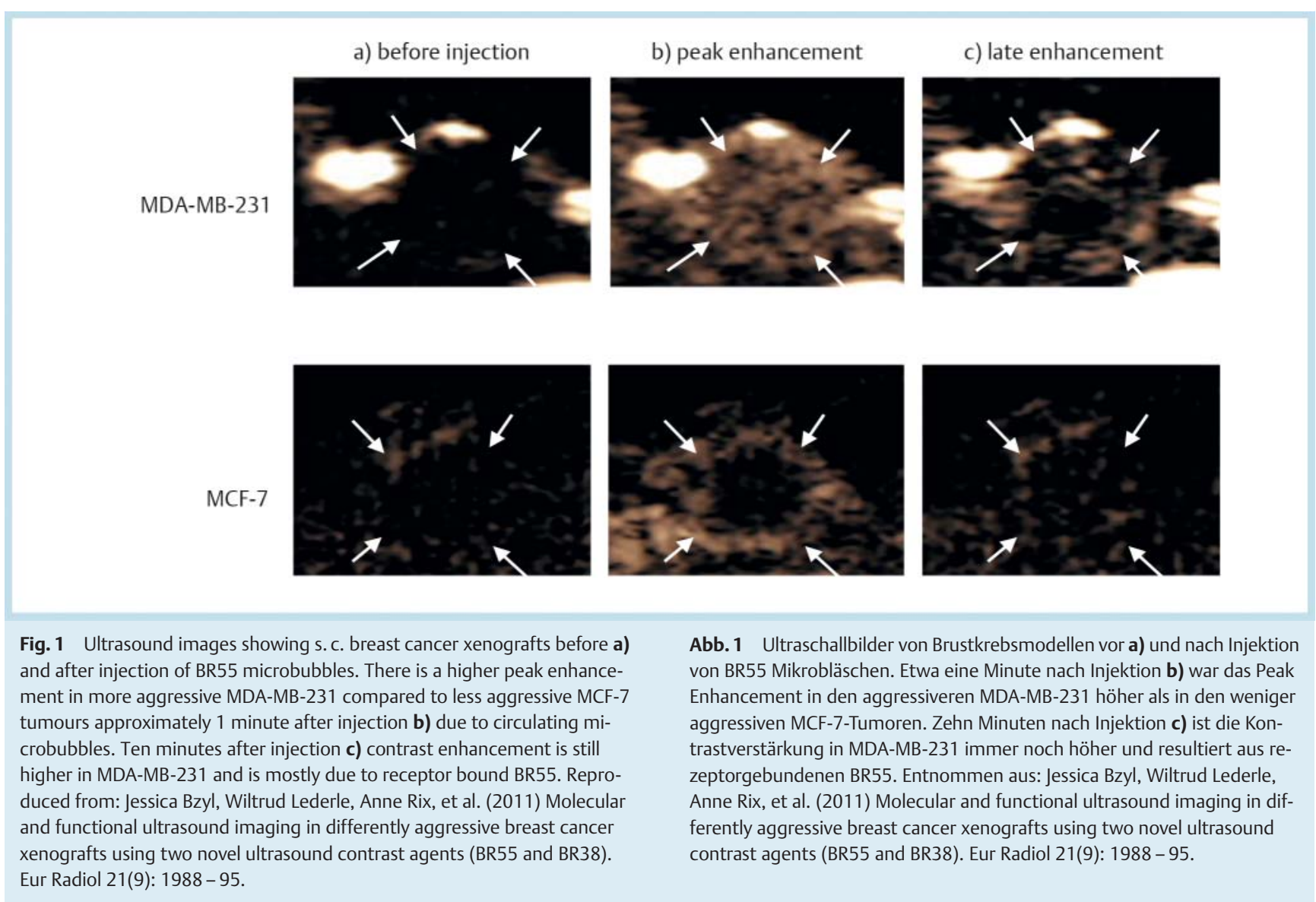

served in the liver which led to their rapid clearance from the blood. The fast elimination of freely circulating microbubbles is strongly desired in order to minimize background signals, as BR55 is designed to assess VEGFR-2 expression.

In highly aggressive, estrogen-independent MDA-MB-231 and less aggressive, estrogen-dependent MCF-7 breast cancer xenografts, both BR55 and BR38 proved to be very well suited for distinguishing and characterizing the different angiogenic activity. Although the more aggressive breast tumors showed a significantly higher rBV compared to the less aggressive model determined by functional ultrasound using BR38, the differences in the angiogenic activity between both tumor models were more distinct with the molecular information obtained with BR55 molecular ultrasound imaging ( $\bullet$ Fig. 1). All data was validated by quantitative immunofluorescence.

In the second study 3-dimensional molecular and functional ultrasound imaging comprising the whole of small developing MCF-7 tumors of only $2 \mathrm{~mm}$ in diameter compared to larger tumors was performed [2]. Reliable imaging of the VEGFR-2 expression with BR55 microbubbles was possible for all tumor sizes ( $\bullet$ Fig. 2). However, due to the particularly high VEGFR-2 expression in the smallest tumors, molecular ultrasound may detect micro-tumors even more sensitively than larger tumors. These results indicate that molecular ultrasound imaging may improve the detection of small invasive breast carcinomas, which are known to overexpress VEGFR2 on the endothelium [7]. In contrast, the degree of vascularization assessed by functional ultrasound with BR38 was more or less constant in all tumor sizes. This phenomenon was elucidated by immunofluorescence analysis which strongly indicated vessel maturation. Vessel matura- tion is characterized by more stabilized vessels due to a close association of vessel supporting cells with the endothelium, like $\alpha$-SMA-expressing pericytes. Furthermore, vessel maturation is characterized by the down-regulation of VEGFR-2 expression. In consequence, maturing vessels have an enlarged lumen resulting in a higher blood volume. Significantly enlarged and significantly more $\alpha$-SMA positive vessels in larger tumors were observed. In addition, the number of vessels was decreased in the larger tumors compared to the $2 \mathrm{~mm}$ tumors, thus explaining the constant rBV for all tumor sizes measured by functional ultrasound. In conclusion, these two studies show how beneficial molecular ultrasound imaging with clinically applicable microbubbles might be in regards to a noninvasive characterization of breast cancer aggressiveness and an early detection of small breast lesions. 

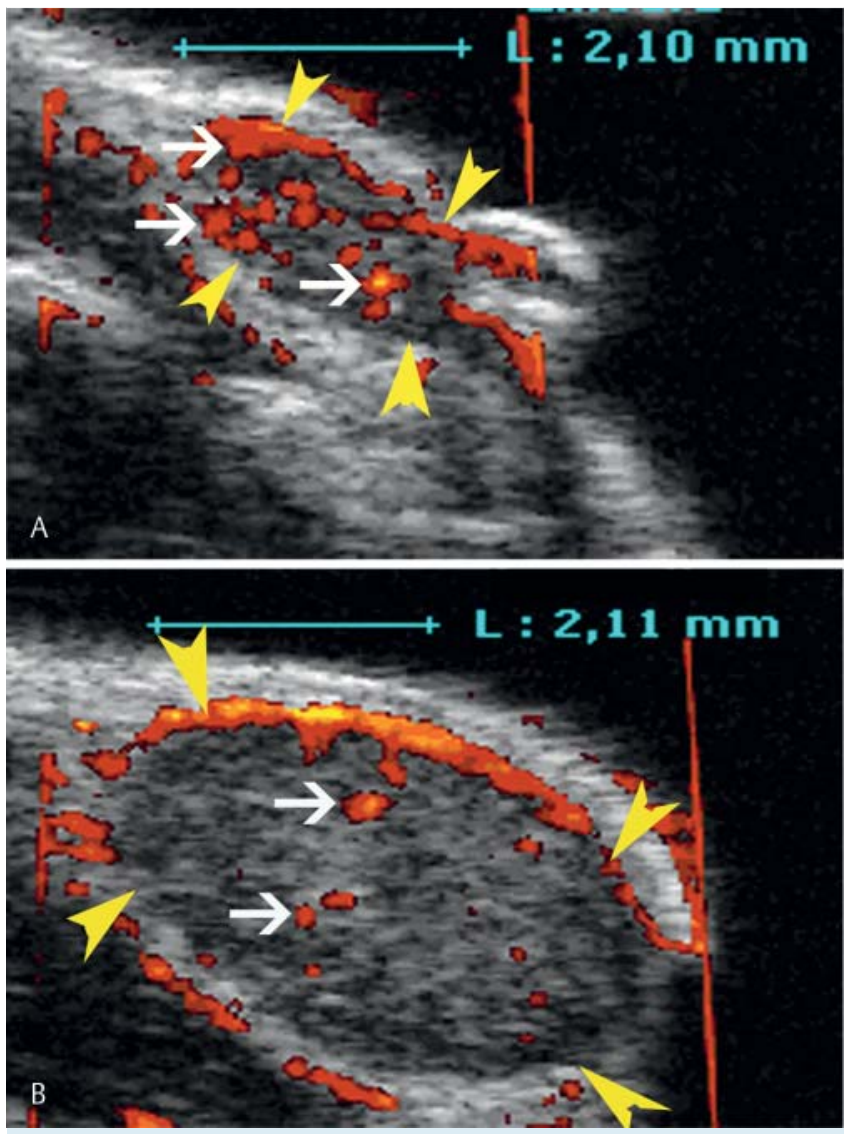

Fig. 2 Representative images of A) a $4 \mathrm{~mm}^{3}$ and B) a $34 \mathrm{~mm}^{3} \mathrm{MCF}-7$ tumor (arrowheads). On the contrast-enhanced image signals of BR55 microbubbles can be seen as a overlay (white arrows show representative signals). In the $4 \mathrm{~mm}^{3}$ tumors significantly more signals of BR55 microbubbles were detected compared with all other tumor sizes. Reproduced from: Jessica Bzyl, Moritz Palmowski, Anne Rix, et al. (2013) The high angiogenic activity in very early breast cancer enables reliable imaging with VEGFR2-targeted microbubbles (BR55). Eur Radiol 23(2): 468 - 75.

Abb. 2 Repräsentative Bilder A) eines $4 \mathrm{~mm}^{3}$ und B) eines $34 \mathrm{~mm}^{3}$ großen MCF-7-Tumors (Pfeilspitzen). In dem kontrastverstärkten Bild sind die Signale der BR55 Mikrobläschen dargestellt (weiße Pfeile deuten auf repräsentative Signale). In den $4 \mathrm{~mm}^{3}$ großen Tumoren konnten signifikant mehr BR55-Signale detektiert werden als in Tumoren aller anderen Größen. Entnommen aus: Jessica Bzyl, Moritz Palmowski, Anne Rix, et al. (2013) The high angiogenic activity in very early breast cancer enables reliable imaging with VEGFR2-targeted microbubbles (BR55). Eur Radiol 23(2): 468 - 75.

\section{References}

1 Bzyl J, Lederle W, Rix A et al. Molecular and functional ultrasound imaging in differently aggressive breast cancer xenografts using two novel ultrasound contrast agents (BR55 and BR38). Eur Radiol 2011; 21: $1988-1995$

2 Bzyl J, Palmowski M, Rix A et al. The high angiogenic activity in very early breast cancer enables reliable imaging with VEGFR2-targeted microbubbles (BR55). Eur Radiol 2013; 23: 468-475

$3 \mathrm{Bzyl} \mathrm{J}$. Establishment of functional and molecular ultrasound imaging with novel, clinically translatable contrast agents for assessing the angiogenic status of two differently aggressive breast cancer xenografts. RWTH Aachen Library 2012

4 Wan CF, Du J, Fang $\mathrm{H}$ et al. Enhancement patterns and parameters of breast cancers at contrast-enhanced US: correlation with prognostic factors. Radiology 2012; 262: 450-459

5 Pillai R, Marinelli ER, Fan $\mathrm{H}$. A phospholipid-PEG2000 conjugate of a vascular endothelial growth factor receptor 2 (VEGFR2)-targeting heterodimer peptide for contrast-enhanced ultrasound imaging of angiogenesis. Bioconjug Chem 2010; 21: 556-562

6 Schneider M, Anantharam B, Arditi $M$ et al. BR38, a new ultrasound blood pool agent. Invest Radiol 2011; 46: 486 -494

7 Smith NR, Baker D, James $\mathrm{NH}$ et al. Vascular endothelial growth factor receptors VEGFR-2 and VEGFR-3 are localized primarily to the vasculature in human primary solid cancers. Clin Cancer Res 2010; 16: 3548 3561 